\title{
Evaluation of the Performance of Asphalt Binder Modified With Nanoparticles
}

\author{
Shaban Ismael Albrka* \\ Department Civil Engineering, University of Near East, North Cyprus \\ Received: 眥 January 22, 2018; Published: 眥 January 31, 2018 \\ *Corresponding author: Shaban Ismael Albrka, Department Civil Engineering, University of Near East, North Cyprus
}

\begin{abstract}
The physical and rheological properties of asphalt binder have been characterized using the conventional tests; (penetration, ductility, and softening point) and dynamic shear rheometer (DSR). In this study, Calcium Carbonate nanoparticles (CaCO 3 ) and Aluminum hydro oxide $\left(\mathrm{Al}_{2} \mathrm{O}_{3}\right)$ nanoparticles have been added to the base asphalt with a concentration of 3, 5 and $7 \%$ by the weight of asphalt. It was found that the addition of $\mathrm{CaCO}_{3}$ and $\mathrm{Al}_{2} \mathrm{O}_{3}$ content has a significant effect on the physical properties of the asphalt, as the penetration reduced up to $50 \%$ for modified asphalt with $\mathrm{CaCO}_{3}$ and $64 \%$ for modified asphalt with $\mathrm{Al}_{2} \mathrm{O}_{3}$. The softening point of modified asphalt binders was increased up to 11 and $12 \%$ for both modifiers respectively compared with the base asphalt binder. Also, the results showed that the storage stability of modified asphalt binders with $\mathrm{CaCO}_{3}$ and $\mathrm{Al}_{2} \mathrm{O}_{3}$ nanoparticles was less than $2.5^{\circ} \mathrm{C}$, which indicates that the asphalt binder and the modifiers having great compatibility. The evaluation of the complex shear modulus of modified asphalt binders shows that the stiffness $\left(\mathrm{G}^{*}\right)$ was increased with addition increase of both modifiers, and the best performance of asphalt binder was found with the addition of $5 \%$ of both nanoparticles. As a result, the use of $\mathrm{CaCO}_{3}$ and $\mathrm{Al}_{2} \mathrm{O}_{3}$ nanoparticles can be considered a suitable alternative additive to modify asphalt binder.
\end{abstract}

Keywords: Calcium carbonate nanoparticles; Dynamic shear rheometer; Modified asphalt binder; Storage stability

\section{Introduction}

Asphalt is a dark brown to black cementation material in which the predominating constituents are bitumen, which occurs in nature or is obtained in petroleum processing. Asphalts are viscous liquids or solids essentially consisting of hydrocarbons and their derivatives, which soluble in carbon disulfide [1,2]. They are substantially nonvolatile at ambient temperature and soften gradually when heated. Asphalt has been used for thousands of years, and it is important as a valued engineering material continues to increase. Bitumen has been widely used in the construction of highways and road network, so in that way, asphalt should resist stresses due to traffic loads and low temperature [3]. Due to the limitation of temperature susceptibility, the low, intermediate and high temperatures and temperature performance of the asphalt need to be enhanced. Therefore, modification of base asphalt is necessary to improve the performance of material [4-6]. There are several types of asphalt modifiers, including rubbers, sulfur, polymers, fibers, and nano materials [4,7,8]. Recently, nanotechnology has rapidly been incorporated into the field of asphalt binder with different kinds of nanomaterials being used to modify asphalt and asphalt mixes. It found that nano materials can enhance the performance of asphalt binder and mixture. A study conducted by You et al. Found that nanoclay modified asphalt could reduce the strain failure rate and increase the stiffness (shear complex modulus) of base asphalt $[8,9]$. Also, using single-wall nano tube materials (SWNT) to modify the asphalt binder, show that the performance grade of the modified asphalt binders increased. Also, the elastic element of complex modulus of the base asphalt was less than the modified asphalts [10]. Based on the study presented by Hui Yao et al. using nano silica to modify asphalt, they found that the addition of nano silica decreases the viscosity rates of unmodified asphalt slightly. Lower and higher viscosity values of asphalt have an influential role in determining the mixing and compaction temperatures. Moreover the addition of nano silica able to reduced and delayed the aging process [11]. 


\section{Experimental Design}

\section{Materials}

Materials were used to produce some laboratories mixed; Base bitumen binder used in this study was $60 / 70$ penetration grade, while the nanomaterials were aluminum oxide nanoparticles (Al203) and Calcium Carbonate nanoparticles (CaCO3) white powder were supplied from China. The physical properties of the base bitumens binder and nanoparticles are shown in (Table 1 \& Figure 1).

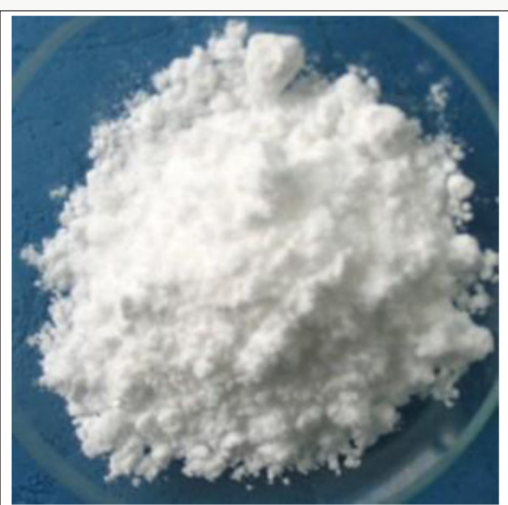

(a)

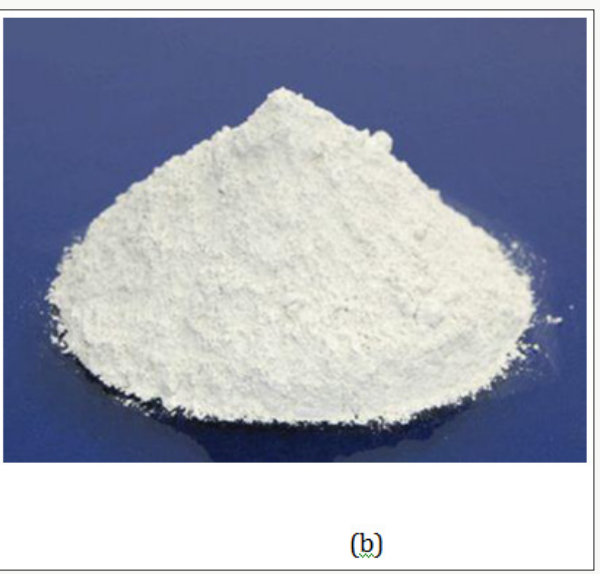

(b)

Figure 1: Modifiers of asphalt binder (a) Al2O3 nano particles (b) $\mathrm{CaCO} 3$ nano particles.

Table 1: Physical properties of the base asphalt and nano particles.

\begin{tabular}{|c|c|c|c|}
\hline Material & Properties & Test Method & Value \\
\hline & Specific Gravity & ASTM D70 & 1.03 \\
\hline & $\begin{array}{c}\text { Penetration @ } \\
255^{\circ} \mathrm{C}\end{array}$ & ASTM D5 & 82 \\
\hline Bitumen & $\begin{array}{c}\text { Softening point } \\
\left({ }^{\circ} \mathrm{C}\right)\end{array}$ & ASTM D36 & 46 \\
\hline \multirow[t]{2}{*}{$60 / 70$} & $\begin{array}{l}\text { Viscosity @ } 135 \\
{ }^{\circ} \mathrm{C} \text { (Pa.s) }\end{array}$ & ASTM D4402 & 0.24 \\
\hline & $\begin{array}{c}\text { Ductility }(\mathrm{cm}) \\
@ 25{ }^{\circ} \mathrm{C}\end{array}$ & ASTM D113 & $\geq 100$ \\
\hline \multirow[t]{2}{*}{$\mathrm{CaCO} 3$} & Size $n m$ & - & 40 \\
\hline & form & & Powder \\
\hline \multirow[t]{2}{*}{ Al2O3 } & Size nm & - & 13 \\
\hline & Form & & Powder \\
\hline
\end{tabular}

\section{Preparation of modified asphalt binders}

The base bitumen was heated to $150{ }^{\circ} \mathrm{C}$ and stirred for about $10 \mathrm{~min}$, and the temperature was raised up to $170{ }^{\circ} \mathrm{C}$. Three percentages of both modifiers (3,5 and 7\% by weight) were added gradually to the base asphalt binder with constant stirring at 170 ${ }^{\circ} \mathrm{C}$ under the high shear mixture speed of 5000rmp for $90 \mathrm{~min}$ until it achieves a homogenous asphalt binder blend for each percentage respectively.

\section{Testing Procedures}

\section{Physical properties}

The conventional physical tests, penetration test at $25{ }^{\circ} \mathrm{C}$, Softening point (Ring and Ball) and ductility were conducted according to the American Society for Testing and Materials (ASTM); ASTM D5, ASTM D36, and ASTM D113 respectively.

\section{Storage stability test}

The modified asphalt cement storage stability was measured as follows. The samples were poured into an aluminum foil tube; the height of the tube is $16 \mathrm{~cm}$ in with $3 \mathrm{~cm}$ in diameter. The foil tubes were closed and stored vertically at a temperature of $163 \pm 5$ ${ }^{\circ} \mathrm{C}$ in an oven for 48 hours, therefore cooled at room temperature and divided horizontally into three equal parts. The samples taken from the upper and lower sections were used to assess the storage stability of the ASA modified asphalt cement by determining the sections softening points, if the difference between the top and the bottom parts was less than $2.5{ }^{\circ} \mathrm{C}$, then the samples were considered to have excellent high-temperature storage stability. If the softening points differed by more than $2.5^{\circ} \mathrm{C}$, the ASA modified asphalt binder was considered to be unstable $[12,13]$.

\section{Dynamic shear rheometer (DSR)}

Dynamic Shear Rheometer (DSR) is used to determine the rheological properties of asphalt binder, including complex shear modulus $\left(G^{*}\right)$ and phase angle $(\delta)$, at low, intermediate and high temperatures. These parameters can be used to describe both viscous and elastic behavior of asphalt. The values of $\mathrm{G}^{*}$ and for asphalt binder are highly dependent on the test temperature and frequency of loading. $\mathrm{G}^{*}$ is a measure of the total resistance of a material to deformation when exposed to a sinusoidal shear stress load. $\mathrm{G}^{*}$ consists of both elastic and viscous components. The $\delta$ is an indicator of the relative amounts of viscous and elastic elements. The DSR used investigates the rheological properties of $\mathrm{CaCO} 3$ and Al203 nanoparticles modified asphalt binders using a frequency sweep test. The frequency sweep applied was 0.159 to $15 \mathrm{~Hz}$, and the temperatures within range $45+10$ to $75{ }^{\circ} \mathrm{C}$. One plate was used in the test, $25 \mathrm{~mm}$ diameter spindle with a gap of $1 \mathrm{~mm}$. 


\section{Results and Discussion}

\section{Physical properties}

The penetration value was reduced for all modified binders at $25{ }^{\circ} \mathrm{C}$ compared with the base asphalt binder. The reduction in the penetration value for modified asphalt binders with $\mathrm{CaCO} 3$ was $44.8 \mathrm{~mm}$ to $3 \%, 35.4 \mathrm{~mm}$ for $5 \%$ and 42.4 for $7 \%$ respectively. Meanwhile, it was observed that the reduction in modified binders with Al203 nanoparticles was. The maximum decrease in the penetration was noted with $5 \%$ for both modifiers compared with all asphalt binders. Furthermore, modified asphalt binders give a higher softening temperature compared with base asphalt binder as shown in (Figure 2). Meanwhile, the base asphalt binder has the lowest softening point temperature. The decrease in penetration and an increase in the softening point of modified asphalt binders are a result of the stiffening effect of nanoparticles. In general, the addition of nanoparticles able to enhance the properties of base asphalt up to $5 \%$ of modifier, in the meantime concentration of $7 \%$ shows different behavior as the penetration increase and softening point decreased. It might be due to agglomeration of nanoparticles during the mixing process [14].

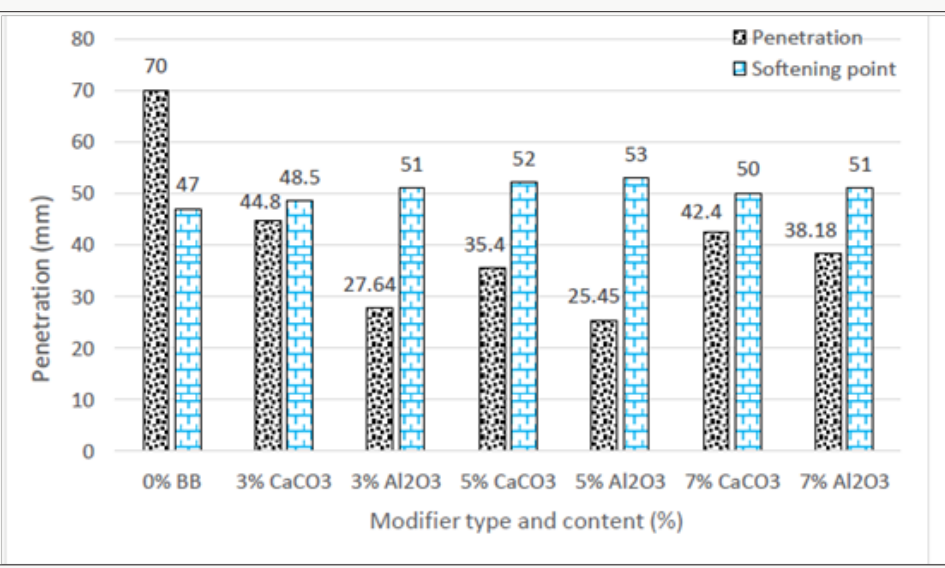

Figure 2: Penetration and softening point of modified asphalt binders.

\section{Storage stability of modified asphalt binders}

The difference in softening point values between the up and down sections of asphalt binders indicates its storage stability. The less value of the parts, the better storage stability for the modified asphalt binders [15]. (Figure 3) shows the storage stability of the base asphalt binder and modified asphalt binders. It was found that the differences in softening points in modified asphalt binders were $1{ }^{\circ} \mathrm{C}$. Therefore, measuring the softening point of the up and bottom sections of each sample, show that the differences between the top and bottom pass the required value as it is less than $2.5^{\circ} \mathrm{C}$ for all binders, this indicates that the nanoparticles modified asphalt binders were quite stable during stored at high temperatures.

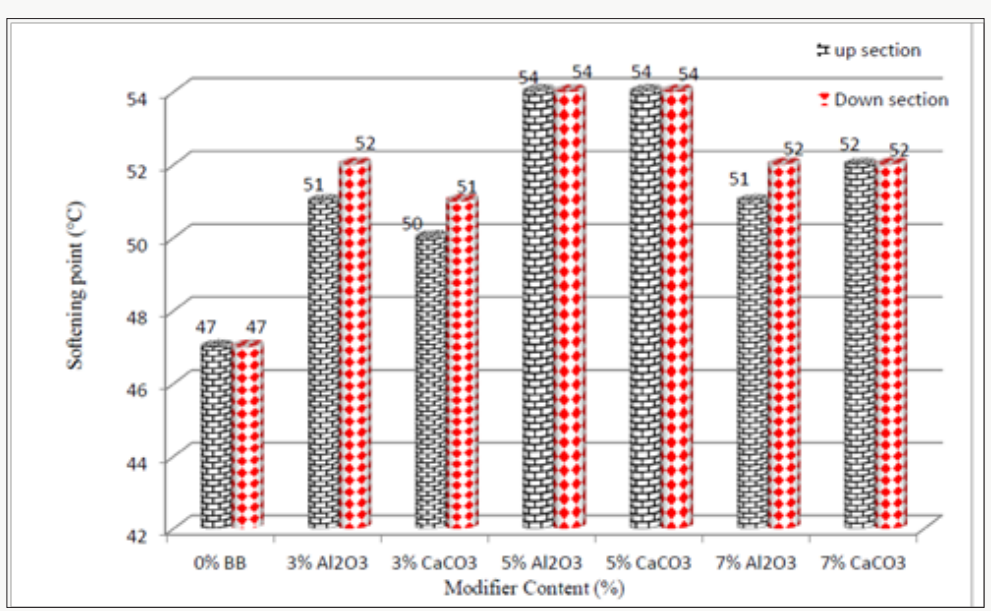

Figure 3: Storage stabilities of modified asphalt binders.

\section{The dynamic shear rheometer (DSR)}

Modify of asphalt binder usually perform in two types of the binders, regarding the compatibility between asphalt and the modifier; the first one, a heterogeneous blend, the asphalt binder, and modifier are incompatible, and they are separated into two phases. The second one is a homogeneous blend, asphalt binder, 
and the modifier are entirely compatible [16]. The evaluation of rheological properties of modified asphalt binder shows a significant improvement in the performance of asphalt binder. (Figure 4) shows that the addition of modifier increases the stiffness of modified asphalt binders. It was noted that the modified asphalt binders whit Al203 nano particles have the highest complex shear modulus among the binders, which mean the highest resistance to deformation at elevated temperatures. Wearase, the base asphalt binder has the lowest complex shear modulus.

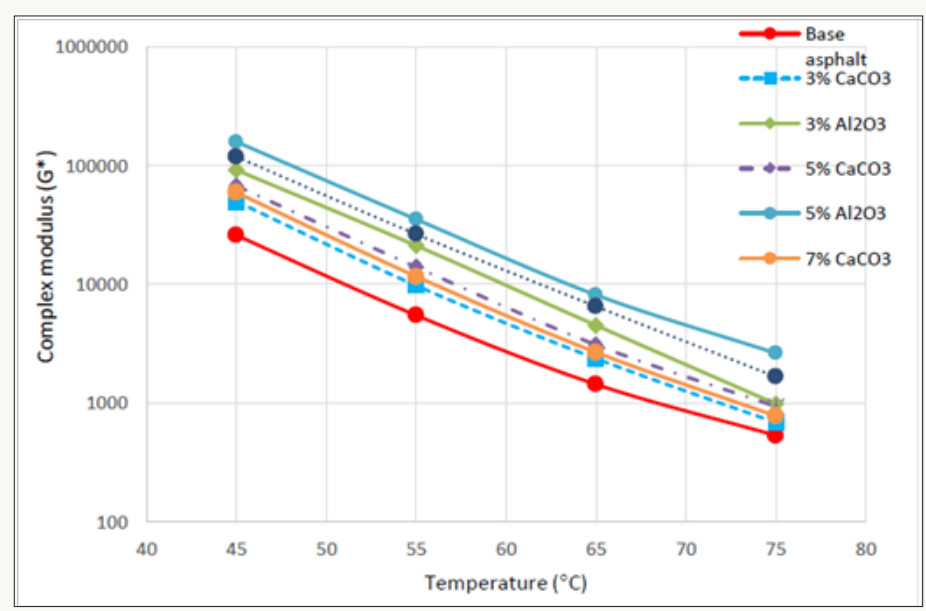

Figure 4: Isochronal plots of modified asphalt binders.

\section{Conclusion}

The evaluation of physical and rheological properties of asphalt binder shows that both modifiers have been successfully improved the physical and rheological properties of modified asphalt binders compared with base asphalt. The penetration decreased and softening point increase, which means the modified bitumen binders become harder compared with base asphalt, and the hardness of binders leads to reduce the temperature susceptibility. Also, it was found that the compatibility between asphalt and nanoparticles is significant, it might due to the uniform dispersion of nanoparticles in the asphalt blends. The result shows that $5 \%$ of both modifiers of asphalt binder can be considered as the best performance of asphalt binder.

\section{References}

1. Lesueur D (2009) The colloidal structure of bitumen: Consequences on the rheology and on the mechanisms of bitumen modification. Advances in colloid and interface science 145(1): 42-82.

2. Read J and D Whiteoak (2003) The shell bitumen handbook. Thomas Telford, UK.

3. Albrka S I, Amiruddin Ismail, Hussin AM Yahia, Mohd Azizul Ladin (2014) Application of Transyt 7f on Signalized Road Junction Networks in Shah Alam and Petaling Jaya. Jurnal Teknologi 69(2): 59-64.

4. Fang C, Ruien Yu, Shaolong Liu, Yan Li (2013) Nanomaterials applied in asphalt modification: A review. Journal of Materials Science \& Technology 29(7): 589-594.

5. Yildirim Y (2007) Polymer modified asphalt binders. Construction and Building Materials 21(1): 66-72.

6. Peters SJ, Todd S Rushing, Eric N Landis, Toney K Cummins (2010) Nanocellulose and microcellulose fibers for concrete. Transportation Research Record: Journal of the Transportation Research Board 2142(1): 25-28.
7. Zare Shahabadi A, A Shokuhfar, S Ebrahimi Nejad (2010) Preparation and rheological characterization of asphalt binders reinforced with layered silicate nanoparticles. Construction and Building Materials 24(7): $1239-1244$

8. Yao H, Zhanping You, Liang Li, Shu Wei Goh, David Wingard, et al. (2012) Performance of asphalt binder blended with non-modified and polymer-modified nanoclay. Construction and Building Materials 35: 159170 .

9. You Z, Julina Mills Beale, Justin M Foley, Samit Roy, Qingli Dai, et al. (2011) Nanoclay modified asphalt materials: Preparation and characterization. Construction and Building Materials 25(2): 1072-1078.

10. Shiman L (2011) Effects of nano composites on the high temperature rheological properties of a PG58 asphalt binder in Proc GeoHunan.

11. Yao H, Zhanping You, Liang Li, Chee Huei Lee, David Wingard, et al. (2012) Rheological Properties and Chemical Bonding of Asphalt Modified with Nanosilica. Journal of Materials in Civil Engineeringn 25(11): 1619-1630.

12. Zhang F, J Yu, J Han (2011) Effects of thermal oxidative ageing on dynamic viscosity, TG/DTG, DTA and FTIR of SBS-and SBS/sulfur modified asphalts. Construction and Building Materials 25(1): 129-137.

13. Al Mansob RA, Amiruddin Ismail, Che Husna Azhari, Mohamed Rehan karim, Aows N Alduri, et al. (2014) Physical and rheological properties of epoxidized natural rubber modified bitumens. Construction and Building Materials 63: 242-248.

14. Ali Shaban Ismael Albrka, Ismail, Amiruddin, Karim, Mohamed Rehan, et al. (2017) Performance evaluation of $\mathrm{Al}_{2} \mathrm{O}_{3}$ nanoparticle-modified asphalt binder. Road Materials and Pavement Design 18(6): 1251-1268.

15. Yu Ruien, Changqing Fang, Pei Liu, Yan Li, Xiaolong Liu (2015) Storage stability and rheological properties of asphalt modified with waste packaging polyethylene and organic montmorillonite. Applied Clay Science 104: 1-7.

16. Leticia Socal da Silva, Maria Madalena de Camargo Forte, Leonardo de Alencastro Vignol, Nilo Sérgio Medeiros Cardozo (2004) Study of rheological properties of pure and polymer modified Brazilian asphalt binders. Journal of Materials Science 39(2): 539-546. 
This work is licensed under Creative Commons Attribution 4.0 License

To Submit Your Article Click Here:

Submit Article

DOI: 10.32474/TCEIA.2018.01.000104

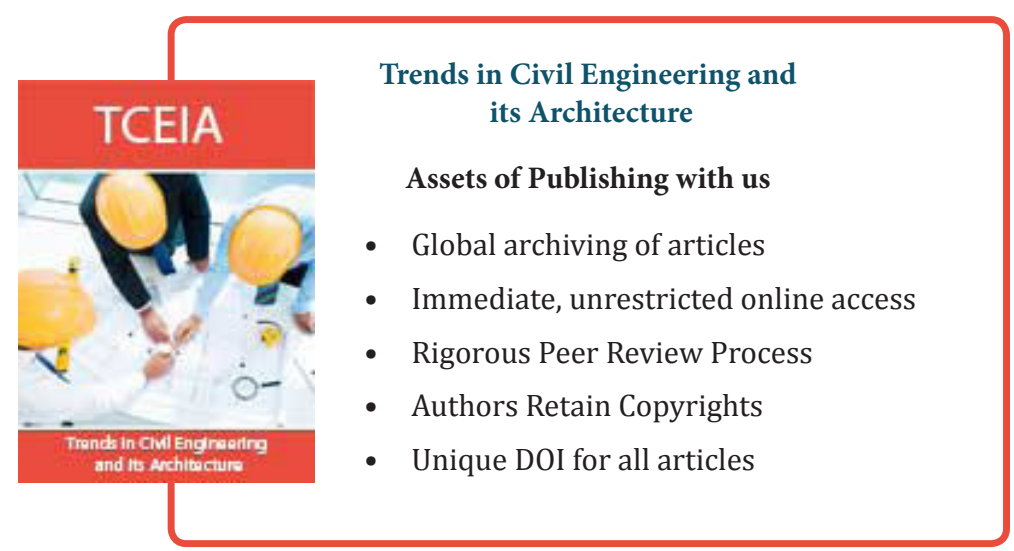

